\title{
Effectiveness of cognitive restructuring technique to reduce academic procrastination of vocational high school students
}

\author{
Wahyu Nanda Eka Saputra ${ }^{*}$ \\ Universitas Ahmad Dahlan \\ *) Corresponding author, ఏ e-mail: wahyu.kons@gmail.com
}

\begin{abstract}
Academic procrastination is a serious problem among student. Academic procrastination refers to delaying in doing assignments and preparing for examinations until the last period of examination time and submission date of assignments. To solve this problem we could use cognitive restructuring technique. The purposes of this research are to gain the description of academic procrastination decrease by implementing the cognitive restructuring technique. This research used a single subject research as the research design. The type of the single subject research which used in this research is multiple baselines. The result of this research shows that academic procrastination had significant decrease by implementation the cognitive restructuring technique. This research gives advice for two parts. First, it will be better if counselor implement the cognitive restructuring technique to decreasing academic procrastination. Second, it will be better if stakeholder of school gives support to counselor for implementation the cognitive restructuring technique to decrease academic procrastination.
\end{abstract}

Keywords: Academic Procrastination, Cognitive Restructuring Technique

How to Cite: Saputra, W. N. E.(2017). Effectiveness of cognitive restructuring technique to reduce academic procrastination of vocational high school students. Couns-Edu: International Journal of Counseling and Education, 2(1): pp. 6-10. DOI: 10.23916/002017025510

(i) This is an open access article distributed under the Creative Commons Attribution License, which permits unrestricted use, distribution, and reproduction in any medium, provided the original work is properly cited. (C2017 by author and Indonesian Counselor Association (IKI).

\section{Introduction}

Delays in academic tasks become a serious problem among students. The phenomenon of delays in academic task called academic procrastination. Solomon \& Rothblum (1984) says that academic procrastination is delay on academic tasks such as writing papers, preparing for exams, reading to complete a task, perform the administration tasks, attendance in class and completing academic tasks.

The phenomenon of academic procrastination among students showed some of the research. Research of Carolia, Yusuf \& Yanuvianti (2012) in one of the universities in Bandung showed that 52.94\% of the subjects are in a moderate, $41.18 \%$ are at a low level, while the remaining $5.88 \%$ are at a high level. Research of Utaminingsih \& Setyabudi (2012) in one of the Tangerang city high school showed that $43.70 \%$ of the students have a high level of procrastination and the remaining $56.30 \%$ had low academic procrastination.

The students in One of the areas in Indonesia, that experiencing of academic procrastination problem is Ngawi, East Java. Academic procrastination scale given to 37 students randomly. Results of data analysis of academic procrastination scale showed that $27 \%$ of students experiencing academic procrastination high 
category, $57 \%$ of students experiencing procrastination medium category, and $16 \%$ of students experiencing academic procrastination lower category.

Academic procrastination is effect on student achievement. Research of Tice \& Baumeister (1997) concluded that academic procrastination impact on the low score of the subjects and the final exam. Research of Steel, Brothen \& Wambach (2000) concluded that students who commit academic procrastination tend to get lower grades in each subject and final exam scores. Research of Popoola (2005) stated that the low academic achievement happened to students who have high and moderate procrastination. Research of Akinsola, Tela \& Tela (2007) stated that academic procrastination was a significant correlation with academic achievement in mathematics.

Besides effect on academic achievement, academic procrastination also affect on academic performance. Research Jiao et al. (2011) concluded that academic procrastination contributes to a decrease in academic performance of students in the form of products study groups. Research of Michinov et al. (2011) concluded that procrastination is highly correlated with lower academic performance of students in the discussion forum. Research of Savithri (2014) concluded that academic procrastination effect on students' academic performance.

Academic procrastination does not happen by itself, but due to certain factors. Research of Chow (2011) concluded that academic procrastination happens to students who have a negative self-evaluation as a form of mind dysfunctional. Research of Flett et al. (2012) concluded that academic procrastination correlated with negative automatic thoughts. Dysfunctional thinking also makes students become a person who easily give up before the task. Personal quitter encourage students delay their academic tasks.

Academic procrastination need to be addressed. One effort to overcome academic procrastination among students is counseling sessions with cognitive restructuring techniques. Cognitive restructuring techniques using the assumption that the responses of behavior and emotional adaptive influenced by beliefs, attitudes, and perceptions (cognition) counselee (Coermir, Nurius \& Osborn, 2009). This study sought to examine whether cognitive restructuring techniques can reduce academic procrastination of vocational high school students.

\section{Method}

This research used a single subject research as the research design. The researcher studies the behaviors of single individuals rather than a group of subjects. There are several reasons this study uses a single subject research design, namely: (1) This study sought to learn the behavior of a single individual rather than a group; (2) study the single subject research design can observe the behavior of research subjects from time to time; and (3) study using single subject research design can control the threat of internal validity (Creswell, 2012). The type of the single subject research which used in this research is multiple baselines. The use of multiple baseline type of intervention aims to diffusion will not occur on the subject of research (Creswell, 2012). Measurement of baseline and intervention phases of data on a single subject research study design with multiple baseline type performed repeatedly (Lodico, Spaulding \& Voegtle, 2010). Subjects in this study are a class XI student of SMK Muhammadiyah 2 Ngawi. Methods of data analysis used in this study is based on experimental design single subject research design with multiple baseline type is a visual data analysis. Visual data analysis is a process of reading a chart to determine whether the intervention has shown a change in the condition before the intervention. There are three important things that must be considered in analyzing visual data, namely the level, trend and variability.

\section{Results and Discussions}

The results of research that considers the trend, the level and variability indicates a student's academic procrastination decreased significantly through the application of counseling intervention with cognitive restructuring techniques. The results of research that considers the trend, level, and such variability visually depicted in figure 1.1 . 


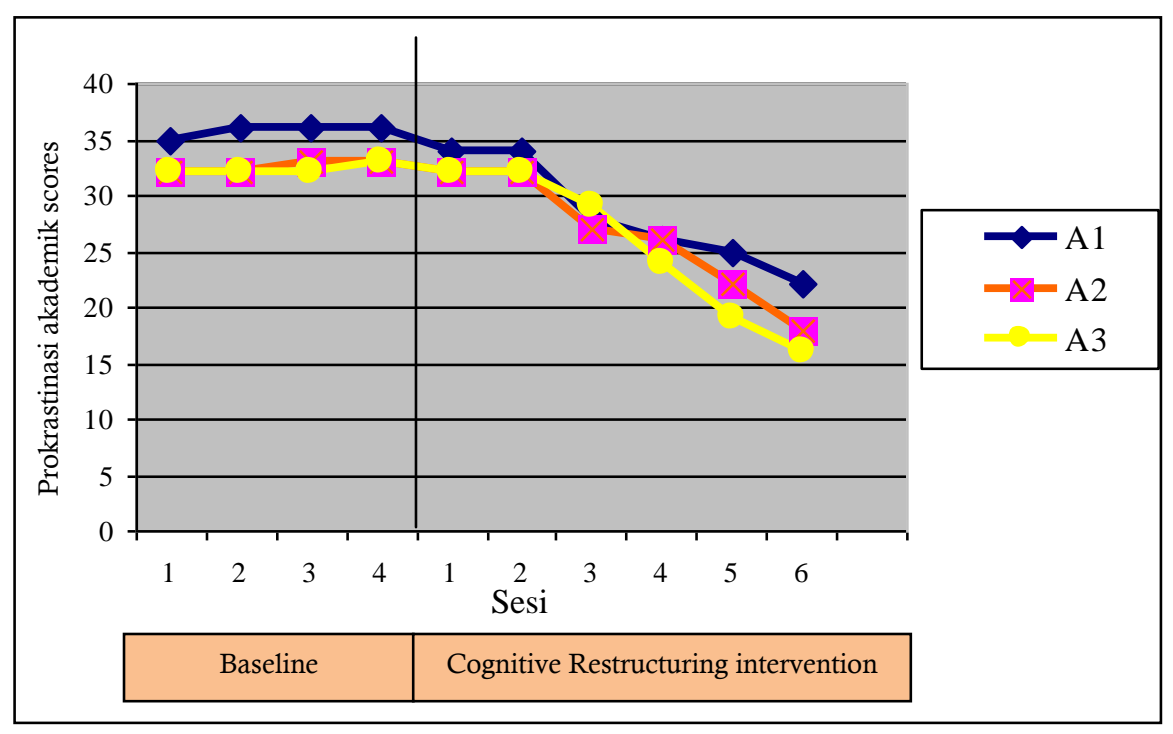

Figure 1 Graph of academic procrastination scores

The study's findings indicate that students' academic procrastination decreased significantly through the application of counseling intervention with cognitive restructuring techniques. Trend research subjects decreased after getting counseling intervention with cognitive restructuring techniques. Changes in levels reached diverse and counseling intervention with cognitive restructuring techniques demonstrated therapeutic in lowering academic procrastination of student. In addition, intervention counseling with cognitive restructuring techniques to experience variability of the data and the decline in academic procrastination scores fluctuated.

Based on the results of previous research studies, has not carried out studies that specifically examine the decline of academic procrastination through the application of counseling intervention with cognitive restructuring techniques. Nonetheless, previous studies involving cognitive restructuring techniques have the same characteristics, namely changing dysfunctional thoughts became more functional in overcoming the problems (Allain \& Lemieux, 2007). Changing patterns of thinking will be a stimulus to changes in behavior (Turner \& Napolitano, 2010).

The study of Marcello, Hilton-Lerro \& Mueser (2009), examines the application of cognitive restructuring as CBT techniques in dealing with Posttraumatic Stress Disorder (PTSD). The result of research indicating cognitive restructuring techniques can be applied as a counseling technique in dealing with individuals who experience PTSD. Cognitive restructuring techniques in the study were designed specifically for individuals with psychotic disorders and mood by focusing on modifying dysfunctional beliefs and behaviors.

The study of Hope et al. (2010) concluded that cognitive restructuring techniques in Cognitive Behavioral Group Therapy can reduce social anxiety. A cognitive restructuring technique used in reducing social anxiety is designed to challenge and change the irrational thoughts automatically become more rational. Automatic thoughts reflected in three fundamental themes, namely experience anxiety, negative self-evaluation and negative evaluation scary.

The study of Rosenberg et al. (2011) concluded that cognitive restructuring program can to solve PTSD experienced by adolescents. Cognitive restructuring programs that are used in addressing adolescent PTSD designed to teach cognitive skills and changing dysfunctional thoughts be functional. Subjects who had undergone counseling sessions, reported high satisfaction and provide positive feedback to the counselor.

The study was conducted Ekennia, Otta \& Ogbuokiri (2013) that concluded cognitive restructuring techniques can be used to reduce nocturnal behavior enuresis. The study explains that cognitive restructuring is CBT techniques that can be observed and practiced by students. Similar to this study, 
cognitive restructuring techniques allow students to absorb and apply the results of counseling outside the counseling session.

Past research has shown that a problematic behavior caused by dysfunctional thoughts. Academic procrastination caused by dysfunctional thoughts (Chow, 2011). Dysfunctional thinking is a denial of the reality and illogical ways of evaluating yourself, others, and the world (Balkis, Duru \& Bulus 2012; Ellis, 2000; Robertson, 2000).

Dysfunctional thoughts on the subject of research trigger very diverse academic procrastination. Corey (2009) explains that humans basically have a tendency to have a mindset of dysfunctional, have confidence in the outer reality, self-deprecating, and avoid the potential for self-actualization. At times like that a human being personally ineffective. Dysfunctional thinking begins with learning illogically obtained from the parents and the culture of the place grew. Dysfunctional thinking will be reflected on the verbalization used. Verbalization illogical show wrong thoughts and verbalize the right shows the right way of thinking.

\section{Conclusions}

Results of visual data analysis by observing the trend, the level and variability of the data, it was concluded that a student's academic procrastination decreased significantly through the application of counseling intervention with cognitive restructuring techniques. Counselors need to identify academic procrastination problems that occur in students in schools and implementing counseling interventions with cognitive restructuring techniques to reduce it. Schools should support and provide facilities to the counselor to intervene counseling with cognitive restructuring techniques and cognitive diffusion.

\section{Acknowledgments}

This article was compiled with the support of several parties. The parties to assist the completion of this article are Prof. Dr. Andi Mappiare AT., M Pd and Dr. Blasius Boli Lasan, M.Pd who helped found the theme of this article. In addition, the support from my wife Prima Rohmadheny, M.Pd who have commented on the technique of writing articles that he wrote for the better governance.

\section{References}

Akinsola, M. K., Tella, A. \& Tella, A. (2007). Correlates of Academic Procrastination and Mathematics Achievement of University Undergraduate Students. Eurasia Journal of Mathematics, Science \& Technology Education, 3 (4): 363-370.

Allain, G. B., \& Lemieux, C. M. (2007). Cognitive Behavior Therapy with Children and Adolescents. Dalam Ronen \& Freeman (Ed), Cognitive Behavior Therapy in Clinical Social Work Practice (hlm. 213-234). New York: Springer Publishing Company.

Balkis, M., Duru, E., \& Bulus, M. (2013). Analysis of the Relation Between Academic Procrastination, Academic Rational/Irrational Beliefs, Time Preferences to Study for Exams, and Academic Achievement: A Structural Model. Euro Journal Psychology Education, 28: 825-839.

Carolia, F., Yusuf, U., \& Yanuvianti, M. (2012). Profil Perilaku Prokrastinasi Akademik Berbasis Cognitive-Behavioral Therapy (CBT) pada Mahasiswa. Jurnal Psikologi Proyeksi, 7 (1): 79-86.

Chow, H. P. H. (2011). Procrastination Among Undergraduate Students: Effects of Emotional Intelligence, School Life, Self-Evaluation, and Self Efficacy. Alberta Journal of Educational Research, 57 (2): 234-240.

Chow, H. P. H. (2011). Procrastination Among Undergraduate Students: Effects of Emotional Intelligence, School Life, Self-Evaluation, and Self Efficacy. Alberta Journal of Educational Research, 57 (2): 234-240.

Coermir, S., Nurius, P. S., \& Osborn, C. J. (2009). Interviewing and Change Strategies for Helpers: Fundamental Skills and Cognitive Behavioral Interventions. USA: Brooks/Cole.

Corey, G. (2009). Theory and Practice of Counseling and Psychotherapy. Belmont: Thomson Brooks/Cole.

Creswell, J. (2012). Educational Research: Planning, Conducting, and Evaluating Quantitative and Qualitative Research. Boston: Peason Education.

Ekennia, C. C., Otta, F. E., \& Ogbuokiri, N. P. (2013). Effect of Cognitive Restructuring Technique and Multi-Component Therapies in the Management of Nocturnal Enuresis Among Junior Secondary Schools. Asian Journal of Management Sciences \& Education, 2 (4): 36-45. 
Ellis, A. (2000). Can Rational Emotive Behavior Therapy (REBT) Be Effectively Used With People Who Have Devout Beliefs in God and Religion?. Professional Psychology: Research and Practice, 31 (1): 29-33.

Flett, G. L., Stainton, M., Hewitt, P. L., Sherry, S. B., \& Lay. C. (2012). Procrastination Automatic Thoughts as a Personality Construct: An Analysis of the Procrastinatory Cognitions Inventory. Journal Rational Emotive Cognitive-Behavior Therapy, 1-14.

Hope, D. A., Burns, J. A., Hayes, S. A., Herbert, J. D., \& Warner, M. D. (2010). Automatic Thoughts and Cognitive Restructuring in Cognitive Behavioral Group Therapy for Social Anxiety Disorder. Cognitive Therapy and Research, 34: 1-12.

Jiao, Q. C., DaRos-Voseles, D. A., Collins, K. M. T., \& Onwuegbuzie, A. J. (2011). Academic Procrastination and the Performance of Graduate-Level Cooperative Groups in Research Methods Courses. Journal of the Scholarship of Teaching and Learning, 11 (1): 119-138.

Lodico, M. G., Spaulding, D. T., \& Voegtle K. H. (2010). Methods in Educational Research: from Theory to Practice. San Francisco: Jossey-Bass.

Marcello, S. C., Hilton-Lerro, K., \& Mueser, K. T. (2009). Cognitive Behavioral Therapy for Posttraumatic Stress Disorder in Persons With Psychotic Disorders. Clinical Case Studies, 8 (6): 438-453.

Michinov, N., Brunot, S., Le Bohec, O., Juhel, J., \& Delaval, M. (2011). Procrastination, Participation, and Performance in Online Learning Environments. Computers \& Education, 56: 243-252.

Popoola, B. I. (2005). A Study of Procrastinatory Behaviour and Academic Performance of Undergraduate Students in South Western Nigeria. Journal od Social Science, 11 (3): 215-218.

Robertson, D. (2000). REBT, Philosophy and Philosophical Counselling, (Online), (http://www.practicalphilosophy.org.uk), diakses 12 january 2017.

Rosenberg, H. J., Jankowski, M. K, Fortuna, L. R., Rosenberg, S. D., \& Mueser, K. T. (2011). A Pilot Study of a Cognitive Restructuring Program for Treating Posttraumatic Disorders in Adolescents. Psychological Trauma: Theory, Research, Practice, and Policy, 3 (1): 94-99.

Savithri, J. J. (2014). Interactive Effect of Academic Procrastination and Academic Performance on Life Satisfaction. International Journal of Science and Research, 3 (3): 377-381.

Solomon, L. J., \& Rothblum, E. D. (1984). Academic Procrastination: Frequency and CognitiveBehavioral Correlates. Journal of Counseling Psychology, 31 (4): 503-509.

Steel, P., Brothen T., \& Wambach, C. (2000). Procrastination and Personality, Performance, and Mood. Personality and Individual Differences, 30 (1): 95-106.

Tice, D. M., \& Baumeister, R. F. (1997). Longitudinal Study of Procrastination, Performance, Stress, and Health: the Cost and Benefits of Dawdling. Psychological Science, 8: 454-458.

Turner, R., \& Napolitano, S. M. S. (2010). Cognitive Behavioral Thrapy (CBT). Encyclopedia of CrossCultural School Psychology, 226-229.

Utaminingsih, S., \& Setyabudi, S. (2012). Tipe Kepribadian dan Prokrastinasi Akademik pada Siswa SMA "X" Tangerang. Jurnal Psikologi, 10 (1): 48-57. 